\title{
Erratum to: What Can You Infer from This Example? Applications of Online, Rich-Media Tasks for Enhancing Pre-service Teachers' Knowledge of the Roles of Examples in Proving
}

Orly Buchbinder, Iris Zodik, Gila Ron and Alice L.J. Cook

\section{Erratum to:}

Chapter "What Can You Infer from This Example? Applications of Online, Rich-Media Tasks for Enhancing Pre-service Teachers' Knowledge of the Roles of Examples in Proving" in: A. Leung and A. Baccaglini-Frank (eds.), Digital Technologies in Designing Mathematics Education Tasks, Mathematics Education in the Digital Era 8, DOI 10.1007/978-3-319-43423-0_11

In the originally published version of the chapter, Figure 4 in Chapter "What Can You Infer from This Example? Applications of Online, Rich-Media Tasks for Enhancing Pre-service Teachers' Knowledge of the Roles of Examples in Proving" was portrait oriented and downsized, hence the text was virtually unreadable. The erratum of the book has been updated with the change.

The online version of the original chapter can be found under DOI 10.1007/978-3-319-43423-0_11

O. Buchbinder $(\square)$

University on New Hampshire, Durham, NH, USA

e-mail: orlybuchbinder@gmail.com

I. Zodik · G. Ron

Technion, Israel Institute of Technology, Haifa, Israel

G. Ron

Ohalo College, Katzrin, Israel

A.L.J. Cook

University of Maryland, College Park, MD, USA 


\begin{tabular}{|c|c|c|c|c|c|c|}
\hline 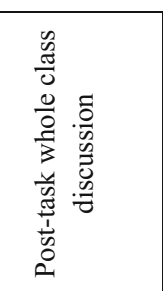 & 1 & \multicolumn{2}{|c|}{ 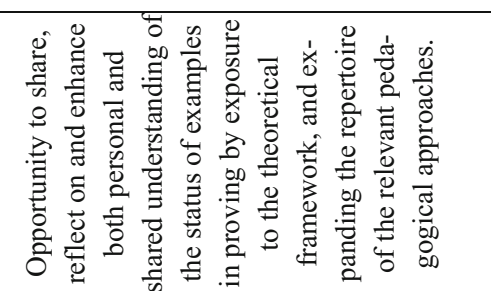 } & \multirow[t]{2}{*}{ ڤे } & 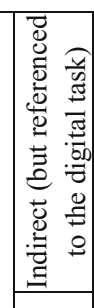 & 苞 \\
\hline 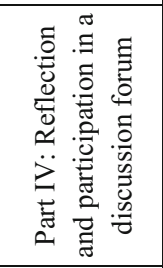 & 1 & \multicolumn{2}{|c|}{ 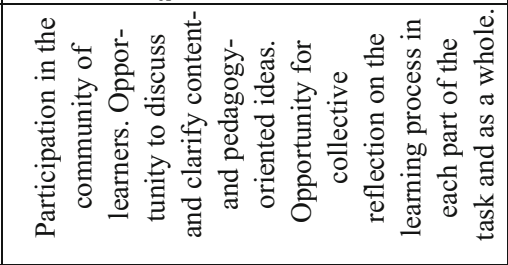 } & & \multirow{4}{*}{ 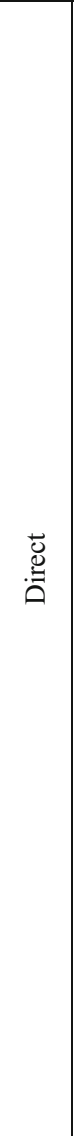 } & \multirow{4}{*}{ 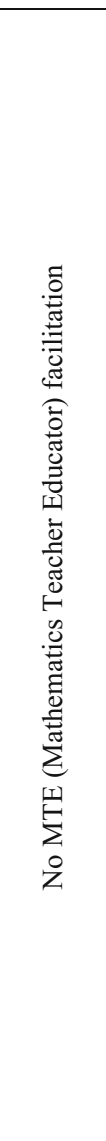 } \\
\hline 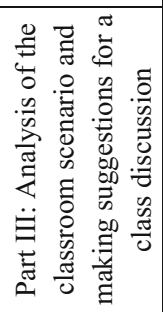 & 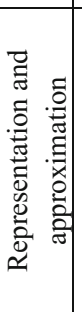 & 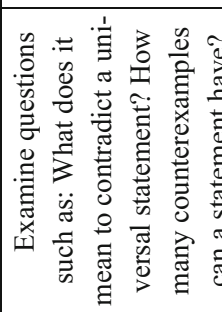 & 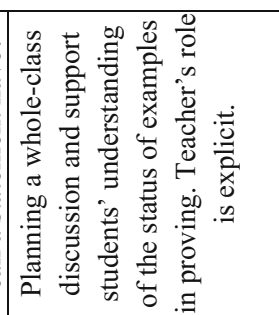 & \multirow{3}{*}{ 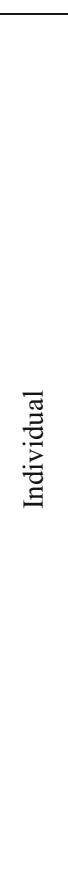 } & & \\
\hline 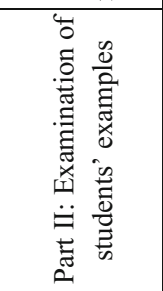 & 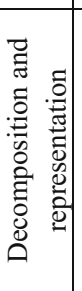 & 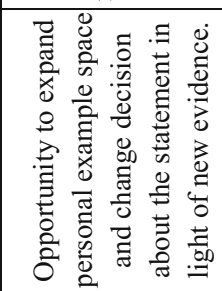 & 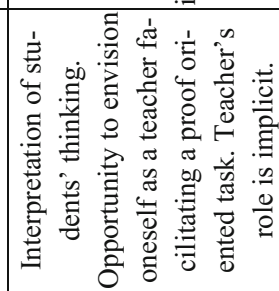 & & & \\
\hline 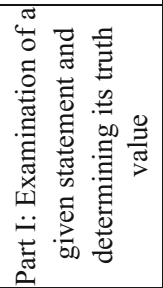 & | & 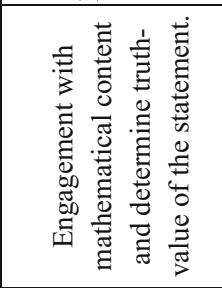 & & & & \\
\hline$/ \stackrel{n}{\mathscr{n}}$ & 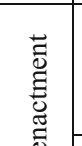 & 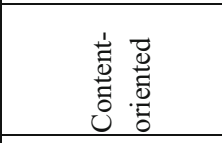 & 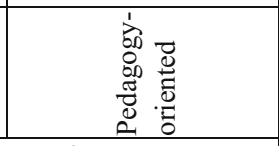 & 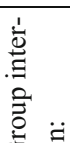 & 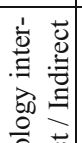 & 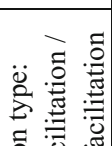 \\
\hline 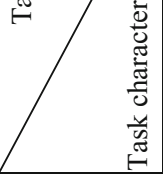 & 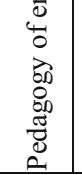 & & 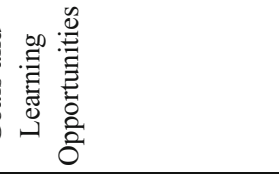 & 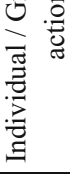 & 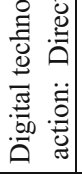 & 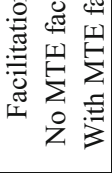 \\
\hline
\end{tabular}

